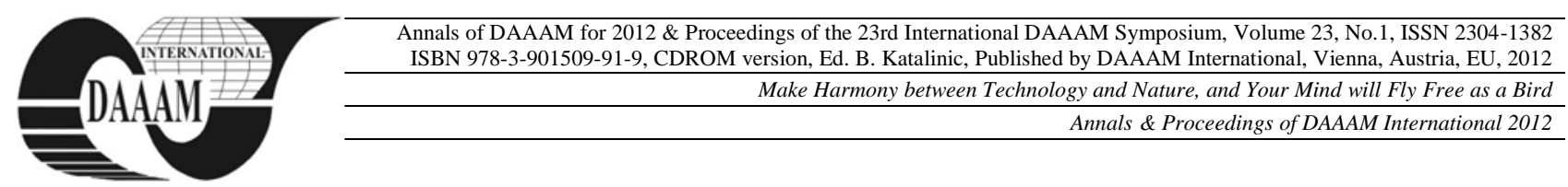

\title{
IMPROVING CULTURALLY DIVERSE ENVIRONMENT IN ORGANISATIONS
}

\author{
MAKRAIOVA, J[ana]; CAGANOVA, D[agmar] \& CAMBAL, M[ilos]
}

\begin{abstract}
Through the acceleration of globalisation processes that are becoming ubiquitous and concerning every business subject, multicultural teams are of a rarity no more and leaders of such teams must understand that acquiring cultural awareness and diversity management skills is one of the premises for gaining competitive advantage and satisfying the employees' need for social cohesion.. The concept presented in this paper goes beyond standard understanding of what cultural diversity management means, as it is not perceived as a set of activities that a business as a whole should be responsible for, but encourage every leader and every person to take responsibility for its own awareness firstly. Only then, after careful and sincere examination of one's own cultural preconceptions and biases and understanding that crosscultural competence is a lifelong learning process it is possible to start recognising one's own cultural mindset before attempting to recognise those of people from other cultures. At this point it is a right time to spread the experience amongst other team members or associates. Various training programs addressing the cultural diversity issues are valuable facilitators and can be considered as an integral part of a successful cultural diversity action plan.
\end{abstract}

Keywords: culture, diversity, management

\section{INTRODUCTION}

Rapid market and economical changes that took place in the past 20 years have brought a significant effect not only into international trade but have also influenced everyday life, resulting in different cultures interactions and requiring specific managerial competences. These dramatic changes bring both opportunities and difficulties, but all of them are particularly challenges for a companies' management. As workplaces in Slovakia have become more diverse, multicultural management and intercultural management competencies have gained increased prominence. This importance stems from the fact that the world is not a homogenous monoculture and organisations increasingly face two simultaneously evolving issues as the challenges presented when companies move to new, often culturally different locations and increased labour mobility resulting in diverse workplaces where people from different cultural backgrounds share their work experience [1]. Multicultural aspects are largely associated with human capital and people at work are the most important asset and a bearer of all those important functions and values, therefore it is of great importance to reinforce such managerial competences that will help to develop understanding and tolerance towards cultural diversity and gain another competitive advantage in the form of staff satisfaction and high performance of employees.
The aim of this paper is neither to describe all those key multicultural managerial competencies, this has already been done within prior survey and will be referred to later, nor to categorise different cultures by type, but offer a basic instruction how to cope with cultural diversity within business. Cultural encounters can appear within the higher level positions, when for instance a parent company sends its expatriates to another country to help start or run another branches or subsidiaries, but are also represented in recruiting and hiring production workers from other countries. Steps to provide better adaptation management of production workers must be initiated precisely by company management. The staff, which will be in everyday contact with those people coming from other countries, must undergo training in order to manage working with them. They must be available to help the newcomers to adapt to all new aspects of the work positions and new culture, bearing in mind the fact that they might have low or no knowledge of the official language spoken in new country. But the language barrier is only the top of the iceberg, the most visible one, but not the only one. When managing and leading people with diverse cultural stereotypes, supervisors have to meet much higher demands, therefore it is recommended for them to gain knowledge and initiate or take part in training to support the development of multicultural understanding. The sooner they understand and accept cultural diversity in a workplace and see it as an advantage, the sooner they can start to pass the skills and knowledge. Supervisors should place focus on this matter. The aim of every business is nothing more than to keep employees satisfied, regardless of their cultural background. But it is necessary to bear in mind all those specific conditions these people must overcome and handle. And be prepared in advance the variety of possible situations to be encountered.

\section{WHO IS A MULTICULTURAL LEADER?}

There are specifically a few main possible ways how a manager can be assigned the status of "multicultural". In general every organisation that is involved in international business can be considered "multicultural" given the multicultural customer or contractor base or in other words operating in international market space or negotiating space. But the truly "multicultural" managers or leaders are engaged to a greater extent. They must either work with a team of culturally diverse people or be an expatriate to another country. Whatever the case is, 
working with a multicultural team means, besides other, also taking responsibility for team members' personal satisfaction and fulfilment, individual performance as well as group effectiveness.

\section{IMPROVING THE DIVERSITY CLIMATE IN A WORKPLACE}

A part of a research that was conducted in a year 2010 in Slovakia and involved several enterprises and public institutions with a large sample of participants from lower to top managers as well as common employees became a basement for considering the proper guidance for those who deal with cultural diversity in the workplace, particularly managers. One of the main targets of the research was to identify which managerial competencies are highest rated and at the same time which are considered to be less important for everyday dealing with and managing the international employee base. The research came up with results that are shown in Fig. 1. Following the research it is possible to determine those management competencies which are regarded as most important within Slovak enterprises. It is clear that communication and language are regarded as the most important traits for the effective management [1].

On the other side of scale the critical thinking and managing stereotypes can be found. It can be logically concluded that managers in Slovak enterprises would place high importance upon language as many multinational organizations have opened subsidiaries in Slovak during the past decade and there are still only a few multicultural workplaces and therefore day to day language and communication challenges are of greatest importance before developing policies and practices such as diversity awareness [1]. Although language and communication skills are very important those competencies focusing on embracing multiculturality should not be forgotten or underestimated.

If a closer look is taken at what makes a good multicultural leader, it is evident that job-related skills, expertise or a well-organised and extensive training, although it is recommended to be an integral part of the whole process, is not enough. It must be some personal preconditions, but definitely it must be a sincere desire for intense preparation and solid personal commitment, which is an on-going, continuous process, consisting of few steps. Prior to introducing this concept, there are several diversity related terms that require explanation or definition firstly, as they all will be recalled later in the text.

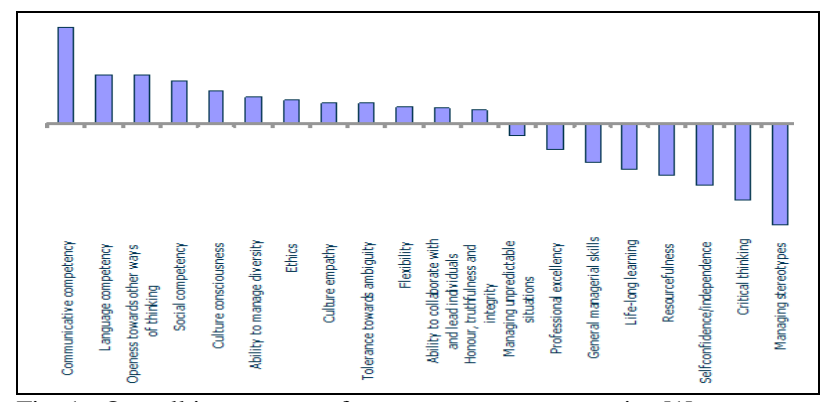

Fig. 1. Overall importance of management competencies [1]

\section{Culture}

There are many various definitions of this term, from biological, through sociological, anthropological, up to artistic. One of the most famous multicultural gurus G. Hofstede says that: "Culture is a collective programming of the mind that distinguishes the members of one human group from another" [2]. Some authors interpret culture in more imaginative way. For instance F. Trompenaars thinks of a culture as layers of onion, the closer to the core of it, the more difficult to identify from outside as well as inside since these unexamined beliefs and assumptions has disappeared from our conscious mind [3].

\section{Diversity management}

"The ongoing process or incorporating the recognition of workforce differences into all core business management functions, communications, processes and services to create a fair, harmonious, inclusive, creative and effective organisation" [4].

\section{Corporate culture}

Culture is considered to manifest itself on different levels, with a national culture on the top of it. "The way in which attitudes are expressed within a specific organisation is described as a corporate or organisation culture" [3]. The basic reason for distinguishing corporate culture from other levels is that within every business can be found differences in many organisational attributes and no two organisations has the same culture.

The concept specifies few steps to be performed simultaneously and continually that be helpful and useful not only for multicultural managers but also all employees within existing or planned multicultural teams. Possibly all suggested advice and guidance can serve and be applied to both, leaders and subordinates.

\subsection{Current position on corporate culture scale}

The very first step of the concept is the necessity to find yourself, your starting point on the Organisational Comfort Continuum according to the theory of $\mathrm{P}$. Johnson. She believes that everyone within an organisation can find their self somewhere along the scale, called the CORPORATE CULTURAL CONTINUUM, see Fig. 2.

On the extreme left side of the continuum, you will find the individuals who have dominating cultural influences that are extremely different from the mainstream cultural organisation. It is most likely that these individuals come from considerably different cultures and know very little about the corporate culture of a certain company, they work for.

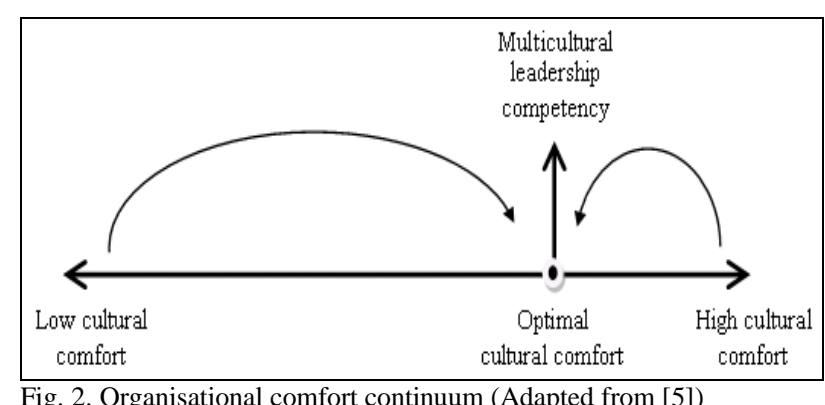


On the extreme right side of the continuum, you will find the individuals who are very comfortable, knowledgeable and skilled within the corporate culture. Although it seems these people might not have any problems with managing cultural diversity, they also need to make some adjustments to become better multicultural leaders, as they might feel so familiar with the present corporate culture, particularly if they are of its own culture, that they become unaware of understanding the needs of diverse workforce. This model must be applied for every single organisation separately as one individual may experience a different corporate comfort level when comparing more than one business. As seen on the figure, the adjustment level for the individuals at the far right is generally lower than for the ones who find themselves at the far left of the continuum. Usually these people have the most cultural differences from the mainstream leadership or organisational climate. (Based upon Everyone is multicultural, Pamela Johnson, 2006 [5])

This point is necessary, as in every situation when steps towards change or improvement are about to take, to help identify where an individual's present position is. However simple this step may look, it is very important and without considering it, it is not possible to continue developing in a right direction.

\subsection{Multicultural self-awareness}

When the identification of one's present position has been made, this is time to move forward. Building awareness of one's own culture and raising the awareness of other cultures is what must be improved on a personal level. This step on the picture represents the arrows from both sides of continuum pointing to the optimum from which the next steps should proceed.

Awareness of one's own culture means getting to know and being conscious of one's own value, its pros and cons, the contributions to a global effectiveness and well-being. Raising awareness of other cultures means the same, only from the opposite perspective. It is a deliberate and conscious process of learning about other people's cultural background and studying various cultural dimensions.

Moreover one is advised to develop an enthusiastic and positive frame of mind free of any prejudices, stereotyping and discrimination, bearing in mind that putting together an effective diverse team will lead to an appreciable personal enrichment as well as considerable business competitive advantage. This way an individual will start to see own identity in a broader context and after then appreciate the uniqueness of all. The effort of any individual taken towards expanding the horizons of cultural knowledge must be more descriptive than evaluative, free from straightforward comparisons between each other and inappropriate judgements on what is better or worse. The best way how to do this, aside from research, formal study or travelling to other part of the world is simply by get to know the person and ask questions. Genuine and sincere interest with respectful curiosity without prejudgement and criticism is usually understood and appreciated.

\subsection{Raising others' awareness}

Once the sincere desire in approaching and knowing other cultural influences has started to take place, individuals can pass on this knowledge and share this enthusiasm with others, either subordinates or colleagues, regardless of whether within an existing group or when expanding or building the multicultural team. It is crucial for all to understand that being a part of a truly multicultural team is not only the competitive advantage for a company but also a personal enrichment. People within working teams should be encouraged to talk about diversity, different worldviews, perceptions and other issues regarding cultural differences with those coming from culturally different environment and at the same time be willing to share about themselves in a twoway process of mutual learning. Two-way information sharing, when done appropriately, is the key to becoming culturally sensitive and skilled, as well as building multicultural trust and organisational comfort. This process can be seen on the Fig. 2. as the upward pointing arrow starting from optimal cultural comfort and making it to the top of multicultural leadership.

\section{USEFUL TIPS HOW TO FACILITATE RAISING MULTICULTURAL AWARENESS}

While getting to know other cultures, several models and concepts can be used as a starting point for learning, e.g. Richard D. Lewis's model, where he categorises all nations into 3 groups (Multi-active, Linear-active and Reactive) with overlapping of some cultural categories and hybrid types [6]. Further typology models are Hofstede's multidimensional cultural model and Trompenaars's 5-dimensions cultural model; however it is not recommended to stick to any of them to a large extent as this generalisation works perfectly with the larger groups of people but might fail when applying to individuals.

Another important consideration when working with and managing cultural diversity is to understand the emotional states that occur when people cross borders [4]. The new environment for people coming to other country means an excitement but also some kind of distress or even dread. There is adjustment that needs to take place and most likely they will go through various states of mind before reaching complete comfort. These states are known as the cultural adaptation stages and are described in Tab. 1.

\begin{tabular}{|c|l|}
\hline \multirow{2}{*}{ Honeymoon } & Differences are perceived as fascinating \\
\cline { 2 - 2 } & $\begin{array}{l}\text { Excitement, Discovery, Curiosity, } \\
\text { Euphoria }\end{array}$ \\
\hline \multirow{2}{*}{ Disintegration } & $\begin{array}{l}\text { Differences are impactful and begin to } \\
\text { intrude }\end{array}$ \\
\cline { 2 - 2 } Confusion, Isolation, Apathy, Withdrawal \\
\hline \multirow{2}{*}{ Reintegration } & Differences are rejected \\
\cline { 2 - 2 } Adjustment & Frustration, Anger, Hostility, Exclusion \\
\hline \multirow{3}{*}{ Biculturality } & Differences are legitimised \\
\cline { 2 - 2 } & $\begin{array}{l}\text { Self-assurance, Relax, Confidence, } \\
\text { Independence }\end{array}$ \\
\hline & Differences are valued and enjoyed \\
\cline { 2 - 2 } & $\begin{array}{l}\text { Trust, Full acceptance of all aspects of a } \\
\text { new culture }\end{array}$ \\
\hline
\end{tabular}

Tab. 1. Adaptation process stages (Adapted from [7]) 
Every stage from psychological point of view is represented with specific perceptions, emotions and behaviours. In multicultural workplaces, everyone is either directly experiencing these emotions and displaying the behaviours described in the schema, or is affected to some extent by another team members adapting to a new environment. Understanding the behaviours and feelings can help to understand why people act a certain way in certain situations and therefore being able to recognise that these expressions are just a result of adaptation process is one of the important skills of those who deal with cultural diversity.

All these steps, starting with understanding one's own culture dimensions, continuing with traits and learning about other cultural ending with passing the acquired knowledge further onto team members can be realised with the support of trainings and workshops or with minimum effort searching for basic multicultural guidance or useful self-study materials directly on the internet. Various training programs can help in guiding leaders and diversity involved employees through every step on the road to recognising and exploring multicultural issues. Some authors and researchers believe that completing cross-cultural training should be mandatory for all diversity involved employees, if not for the whole organisations and therefore they predict an increasing demand for cultural diversity training.

\section{EVALUATION}

The concept builds upon the belief that every person who wants to succeed within a business environment must take responsibility for their own learning and improving and not only passively wait for actions to be offered from the side of a company. It is about building an individual action plan, which could be helpful particularly for those acting as managers in organisations. They are increasingly responsible for minimising the disadvantages and maximising the advantages of workforce diversity to ensure social cohesion as an essential component of organisational effectiveness. It has been mentioned several times that accomplishing goals for managing diversity brings benefits on both sides, personal and business as well. Successfully managing cultural diversity of the workforce contributes to gaining sustainable competitive advantage, that is to say something that is better than of competitors, valuable to customers and all employees, rare in the industry and finally difficult to acquire or imitate [4]. Gaining diversity based competitive advantage reflects itself in many areas, starting in organisational development, continuing in people and knowledge management, ending with customer services. Enterprises using diversity management strategies to address the concerns of specific cultural groups can benefit from:

- Reducing workforce turnover and absenteeism.

- Increasing effectiveness in recruiting and retaining international qualified employees.

- Increasing cultural adaptability of expatriates.

- Improving team performance, flexibility, cohesion.

- Avoiding stressful and unproductive conflicts.

- Improving the environment for learning and sharing.

- Enhancing competition internationally.

The competitive advantage lies in a fact that working teams with diverse sets of experiences, mental models, thinking styles and interpretations produce more options and more creative solutions to problems and challenges than homogeneous groups [4].

\section{CONCLUSION}

It is important that industrial businesses acknowledge the economic and social contribution of a culturally diverse workforce and with this regard develop the most possible effort to manage diversity on every level. More importantly, an organisation cannot be a leader in diversity if its employees' minds are not on the same level. Corporations can facilitate the best diversity and inclusion programs, but if the managers and employees do not do their part, disagree with underlying principles, or undermine the program's basic philosophy and goals, the diversity efforts are meaningless. A diversity-driven corporate culture must be inclusive of diversity-driven people [5]. The aim of this paper was to enable people, either leaders or individuals who deal with cultural diversity on everyday basis or occasionally, to better understand the importance and value of diverse workforce and learn how to improve workplace performance and environment. It was identified that the paper findings are limited by a lack of a primary research and instead only focus on existing secondary research. The findings will be developed further by conducting a primary research study and the subsequent findings will then be used as a basis to formulate the research direction of the dissertation thesis. This will focus on establishing the correlation between the performance of working teams and the extent of the multicultural climate.

\section{ACKNOWLEDGEMENTS}

The paper has been published as a part of submitted VEGA project No. 1/0787/12 ,The identification of sustainable performance key parameters in industrial enterprises within multicultural environment".

\section{REFERENCES}

[1] Cagáňová, D.; Čambál, M.; Šujanová, J.; Woolliscroft, P. (2012). The Multiculturality Aspects and Human Capital Management within Slovak Industrial Enterprises, Proceedings of the 4th European Conferences on Intellectual Capital, ECIC 2012, Arcada University of Applied Science, 23-24 April 2012, Helsinki, Finland

[2] Hofstede, G. (2003). Cultures and organizations, McGraw-Hill International, ISBN: 0071664189, London, UK

[3] Trompenaars, F., Hampden-Turner, C. (2000). Riding the Waves of Culture, Nicholas Brealey Publishing, ISBN: 0786311258, London, UK

[4] Australian Multicultural Foundation (AMF) (2010), Managing Cultural Diversity, Australian Multicultural Foundation, Training Program Resource Manual. Available at http://amf.net.au/library/uploads/files/MCD_Training_Program_R esource_Manual.pdf Accessed: 2012-08-20

[5] Johnson, P. (2006). Everyone is multicultural, iUniverse, ISBN: 0595385188, New York, USA

[6] Lewis, R. (2002). When Cultures Collide, Nicholas Brealey Publishing, ISBN: 190483022, London, UK

[7] Casse, P. (1984). Training for the Cross-cultural Mind, SIETAR International, ISBN: 0933934061, Washington D.C., USA 